\title{
Lecturas posibles sobre la construcción del actor económico
}

Nicolás Gómez Núñez

Sociólogo

Magíster en Desarrollo Humano

En tres breves capítulos, el artículo pone a disposición las ideas básicas que cruzan la reflexión sobre las actividades económicas que las personas realizan en condiciones de pobreza, destacándose la preocupación sobre si estos desempeños pueden constituirse en alternativas de crecimiento económico a nivel local o si ellas son actores que inciden en las políticas públicas que organizan los supuestos del desarrollo.

Palabras clave

Actividades Económicas Autogestionadas / Autonomía / Capacitación / Desarrollo Endógeno. 
Abstract:

In three brief chapters, the article displays the basic ideas that intersect the reflection on the economic activities that people perform in conditions of poverty, standing out the concern whether these performances can constitute in alternatives of economic growth at the local level or whether they are activities that affect the public policies which organize the theories of development.

Key words

Self-managed economic activities / Autonomy / Training / Endogenous Development 


\section{Introducción}

$\mathrm{E}$

1 presente artículo busca plantear un conjunto de hipótesis sobre el desempeño de las actividades económicas generadas en condiciones de pobreza, a través de las cuales se pretende saber si estas actividades logran abrir posibilidades para visualizarlas como estrategias que favorecen el empoderamiento de las personas que las llevan a cabo, en circunstancias sociopolíticas donde las turbulencias de la gobernabilidad favorece escenarios complejos para estimar reducciones en la inequidad de la distribución de las riquezas.

Para tales propósitos, hemos organizado un proceder que involucra, en un primer momento, la revisión que en Chile se le ha dado de las actividades económicas autogestionadas por personas pobres y cómo ellas se han ido vinculando con los servicios que le ofrecen otras organizaciones que no pertenecen a sus contextos sociales, económicos o culturales. En un segundo momento, realizamos un ensayo teórico que implica a las dimensiones y variables identificadas en el primer momento como si ellas correspondiesen a un proceso de conformación de agentes sociales que pasan desde un estado básico a otro complejo, en cuyo caso, ocupamos los planteamientos de Durkheim (1960) sobre las Solidaridades, los de Bourdieu (1998) en relación a las "estructuras estructurantes de sentido" que conforman su noción de Habitus y, eventualmente, hacemos uso de las ideas de Cocoon Protector de Giddens (1996) y de Capital Social de Durston (2000). 
$\mathrm{Al}$ entrar en las materias que hemos situado en el primer momento, reconocemos un proceso que le es común a los países de América Latina y el Caribe en sus últimos cuarenta años de historia, a excepción de Cuba, Haití, Puerto Rico y Jamaica, el cual circunscribe el desenvolvimiento de las actividades económicas generadas desde la pobreza y, en términos generales, el diseño de las políticas públicas orientadas a producir crecimiento económico y participación social, el cual está dado por un cambio en la matriz sociopolítica, cuyo indicador relevante es el tránsito desde una agenda pública socialdemócrata a una neoliberal.

Para Chile, al igual que para el resto de los países del ConoSur de América, esta inflexión tuvo un carácter violento con la Dictadura del General Augusto Pinochet. Desde este hecho, podemos identificar dos períodos que confieren un carácter particular a las actividades y asuntos que tratamos: el comprendido entre 1973 y 1989 y el de 1990 a 2004.

Brevemente, podemos señalar que, a partir del 11 de septiembre de 1973, se implementa un modelo económico que pone el acento en la capacidad del mercado como motor del crecimiento, dejando en un segundo plano al Estado como ente regulador y planificador del Desarrollo, rol que había sido considerado como fundamental en la agenda socialdemócrata de los años sesenta; abre nuevas estrategias de obtención de divisas vía exportaciones e inversión de capitales extranjeros, o también llamado proceso de internalización de la economía, con lo cual se altera el proceso de industrialización y, por ende, de sustitución de importaciones; se reduce el gasto fiscal y se implementa un plan de privatización de empresas estatales con el propósito de mantener controlado el déficit fiscal en un momento de decrecimiento del ciclo económico.

Este modelo fue llevado a cabo por un gobierno no elegido democráticamente, el cual cerró el Poder Legislativo y reorganizó la Carta fundamental de la República, 
lo que favoreció, entre otros asuntos, la desarticulación de los sindicatos y cooperativas obreras y campesinas y el no desarrollo de las disciplinas de las Ciencias Sociales, cuyas áreas de investigación se relacionan con la pobreza y su superación.

Por su parte, el período 1990 - 2004 comienza fuertemente marcado por la variable de participación cívica o de "retorno a la democracia". Se elige el primero de los cuatro gobiernos de La Concertación de Partidos por la Democracia, se pone en vigencia el Poder Legislativo, se democratiza la elección de los gobiernos municipales y comienzan lentamente a retomar su curso las disciplinas de las Ciencias Sociales en un universo mayor de universidades. Por su parte, el modelo económico no sufre alteraciones importantes y, entre 1994 y 1998, la economía presenta tasas constantes de crecimiento de 6 por ciento y un porcentaje similar de cesantía.

En ambos períodos, podemos identificar dos tipos de estudios: los que se dedican a ver cómo las personas logran gestar negocios que les permiten obtener ingresos desde situaciones de marginación política y precariedad económica y aquellos que constituyen ejercicios de sistematización que buscan diagnosticar y evaluar la relación entre programas de asistencia y cooperación y responsables de unidades económicas autogestionadas.

\section{a. Actividades económicas generadas en condiciones de pobreza. Lecturas posibles}

En los estudios del primer tipo, realizados entre los años setenta y ochenta, se aprecia una preocupación por conocer y comprender las incidencias que trajo consigo el modelo económico. Ahí se encuentran aquellos que re- 
visaron las consecuencias de las políticas de empleo y los que tomaron a las distintas organizaciones de los sectores afectados por la cesantía y la marginación de la participación política como objeto de análisis. De los primeros, destacamos los resultados de dos investigaciones.

En primer lugar, la investigación realizada por RuizTagle y Urmeneta (1984), cuyas conclusiones apuntan a señalar que el Programa de Empleo Mínimo (PEM) implementado por el Estado, aparte de ser de bajo costo, ayudó a orientar las energías de protesta de los desocupados, constituyó una estrategia precaria de integración social de los trabajadores y, ante la inestabilidad y cuantía de los recursos económicos entregados desde el PEM, las mujeres salieron al espacio público en búsqueda de créditos, desarrollando solicitudes entre los miembros de la familia (padres y parientes) y en las redes locales (amigos y vecinos); y usaron los recursos sociales y económicos colectivos para organizar actividades que les permitieran cubrir las necesidades de alimentación y salud, constatándose ahí el apoyo y amparo de las Organizaciones No Gubernamentales (ONGs) que participaban de las dinámicas del espacio comunal.

En segundo lugar el estudio realizado por Cerda y Cifuentes (1987), que se abocó a revisar el supuesto de que las personas que habitan en sectores urbanos implementan acciones racionales al momento de establecer sus estrategias de compra, cuya lógica les permitiría no sólo planificar sus gastos en alimentos sobre la base de los recursos económicos disponibles y probables, sino que, además, las llevaría a comprar en aquellos establecimientos comerciales que ofrecen a menor precio sus productos. Dicha racionalidad económica estaría organizada sobre las informaciones técnicas que recorrerían las rutinas diarias de los habitantes de una determinada comuna, indicándoles los canales de abastecimiento más baratos y donde todos los consumidores estarían en igualdad de condiciones para entrar y participar en ellos. 
Sobre los datos de los habitantes del estrato socioeconómico bajo de la comuna de La Florida, Cerda y Cifuentes constatan que, aparte de que los gastos en alimentación representaban el principal destino de los recursos económicos de los hogares, la racionalidad económica no se observaba condicionada por los supuestos antes descritos, sino que, más bien, tenía relación con el monto y periodicidad de la obtención de los ingresos, los cuales, en condiciones inestables, no favorecían la planificación de los gastos ni el diseño de acciones racionales destinadas a maximizar los recursos económicos.

En esas circunstancias, ellos identifican un actor económico elemental en las relaciones comerciales: el "local del barrio", y una estrategia comercial: "el fiado". El primero fue visualizado como canal de abastecimiento que hacía posible cubrir las compras de alimentos a precios más altos por parte de los clientes; mientras que, para las mayoritarias mujeres dueñas de los "locales del barrio", sus establecimientos les permitían obtener un ingreso adicional y los productos para abastecer sus hogares, observándose que, en la realización de las tareas administrativas y comerciales, ellas no presentaban un control sistemático.

Por su parte, "el fiado", a la vez que se constituyó en una estrategia comercial apropiada para los ritmos de la microeconomía local, formaba parte de una instancia donde se congregaban relaciones de solidaridad que establecían dependencia entre vendedores y clientes, indicadas en los acuerdos que entre ellos se adoptaban para establecer los precios y fijar los períodos y montos de los pagos.

De esta manera, los estudios muestran que la orientación de las prácticas de consumo y la gestación de actividades económicas están directamente vinculadas a los ritmos que adquiere la obtención de ingresos por parte del mercado de consumo local, el cual, progresivamente, se ha ido conformando por clientes que han entrado en una 
etapa de creciente desproletarización. Así, estas condiciones son aspectos relevantes del carácter de las actividades comerciales donde las mujeres ocupan el rol de dirección, y favorecen el surgimiento de interacciones que indican la existencia de confianzas entre clientes y vendedoras y, por ende, de un tipo particular de organización simbólica del espacio local.

Por su parte, el segundo tipo de estudio estuvo guiado por el concepto de Popular, el cual fue usado como herramienta de análisis y como parámetro para definir las unidades de estudio. En su aspecto analítico, representa la labor por conocer las cualidades dinámicas de la organización suponiendo que este tipo de colectivos podría contener elementos transformadores del orden social y económico vivido en los setenta y ochenta. En consecuencia, los diseños metodológicos que comúnmente son de la clase Investigación-Acción, confeccionaron muestras donde se conjugaron criterios demográficos y socioeconómicos con los de identidad y grupales. Así, las unidades de análisis fueron los Pobladores y las Organizaciones Económicas Populares (OEP).

De las investigaciones realizadas desde este planteamiento, destacamos cuatro conclusiones. La primera se refiere a la mayor disposición de las mujeres por transformarse en protagonistas de las organizaciones basadas en actividades económicas solidarias (Ramírez, 1986, y Ortega y Tironi, 1988), y las consecuencias que dicha participación tuvo para mantenerlas en el tiempo y generar otras actividades que ampliaron los beneficios hacia el crecimiento y desarrollo personal de sus miembros (Hardy, 1985).

La segunda tiene relación con las redes que permitieron a los sectores populares urbanos obtener asistencia material y apoyo socioafectivo para hacer frente a los problemas económicos y sociales, donde se identificó un sistema básico constituido por los miembros de la familia, el que 
llegó a alterar su composición al incorporar a los "allegados" (Ortega y Tironi, 1986) y, en un nivel más complejo y colectivo, varias relaciones sociales con permanencia en el tiempo que se conformaban entre las personas y organizaciones que participaban de las dinámicas del espacio local.

En este nivel, se utilizó, por un lado, el concepto de Pobladores para comprender las consecuencias de la desintegración que los sistemas familiares y comunitarios estaban viviendo como resultado de su distribución periférica en las áreas urbanas, propias del proceso de erradicación de las "Poblaciones Callampas"; la dependencia que tenían con el Estado y los resultados de las políticas de empleo que descomponían la categoría de asalariado como actor político (Tironi, 1987). Por otro lado, se trabajó con el concepto de OEP acuñado por Razeto, Klenner, Ramírez y Urmeneta (1984), que define las "formas y actividades económicas elementales", ubicadas en un nivel micro social y generadas por los sectores populares urbanos. Estas formas y actividades económicas se basarían en un sistema de relaciones entre personas donde prima la cooperación, reciprocidad y donación, mientras que, en los otros sectores, especialmente los de la economía regulada, tendrían mayor relevancia las relaciones mediadas por los intercambios.

De este tipo de organizaciones, destacamos dos de las cinco descritas por los autores, a saber: organizaciones de trabajo o talleres productivos, organizadas por personas que laboran en condiciones igualitarias y sin parámetros claros de funciones y jerarquías para producir y comercializar bienes y servicios, y donde la distribución de los excedentes se decide de manera colectiva sobre parámetros equitativos. Y las organizaciones laborales conformadas por los productores y la de los desocupados y subempleados, las que se diferencian de las organizaciones sindicales por estar orientadas hacia la búsqueda de oportunidades para mejorar las condiciones de los desempeños económicos 
y asegurar sus giros comerciales, más que por establecer instancias de negociación salarial.

Si bien la mayor parte de los estudios se dedicaron a dimensionar los alcances de las OEP, la investigación realizada por Ortega y Tironi (1988) señala que, junto a las que hemos seleccionado, coexistían otras estrategias de obtención de ingresos que le permitían asegurar la subsistencia a los sectores populares urbanos como, por ejemplo: los talleres individuales productivos, el comercio ambulante y los ubicados en las viviendas de los hogares, los cuales se basaban en las capacidades individuales y no en las de pequeños grupos y que, aparentemente, no contaban con los aportes de recursos económicos y servicios técnicos entregados por las organizaciones donantes que no pertenecían a la localidad y (o) a la comuna.

La tercera conclusión rescata la descripción que se realizó sobre la relación entre las OEP e instituciones donantes. Hardy (1985) señala que las donaciones económicas que estas últimas realizan no representan componentes centrales para la organización, sino que, más bien, son relevantes cuando se las considera como relaciones de solidaridad que entregan legitimidad a este tipo de experiencias, favoreciendo un puente de cooperación entre "nosotros" y "los otros".

La última conclusión abarca el debate sobre la viabilidad de estas organizaciones para ser dispuestas como herramientas de superación de la pobreza en contextos sociopolíticos distintos a los que presentaba Chile a fines de los ochenta. Por un lado, se observa que estas organizaciones se encuentran vivas por el carácter inmediato de sus problemas y que, debido a los esfuerzos que ellas demandan y a las utilidades que reportan, se hace poco probable que los miembros lleguen a generar futuros económicos de manera conjunta (Ramírez, 1985), para que así logren convertirse en actores sociales relevantes en el diseño de 
propuestas capaces de alterar el orden social y económico, o a lo que Razeto llamó "Hipótesis Máxima", a saber: "el fenómeno que estamos analizando sería portador de un nuevo modo de organización y de acción transformadora, al menos en forma germinal o embrionaria.., que implica potencialmente la superación de los modos tradicionales de organización popular." (Razeto, 1984).

En este sentido, Campero (1987) reconoce dos límites que se relacionan entre sí. El primero, referido a que en estas organizaciones no participan los hombres desempleados, sino que a ellas se incorporan las personas que tienen menos probabilidades de ser contratadas en el Mercado de Trabajo como, por ejemplo, las mujeres adultas con familia. De ahí que su carácter autocentrado, constituyente del segundo límite, les impida encarnan un proyecto transformador y dinámico en el espacio local, aun cuando los agentes externos intenten sensibilizarlas y "dotarlas" de una visión macro social.

En contrapartida, Razeto (1986) apuesta a organizar una mirada comprensiva de este tipo de fenómeno que, por su carácter y condiciones de funcionamiento, debe utilizar variables, dimensiones y herramientas distintas a las aplicadas cuando se estudia a las empresas que tienen el propósito de maximizar las ganancias monetarias ya que, por ejemplo, se dejaría pasar la acumulación de valores, capacidades y energías creadoras que las personas logran cuando realizan sus labores al interior de estas unidades productivas y, por tanto, no se valoraría la importancia de la autonomía que ellos obtienen cuando alcanzan la meta de la subsistencia.

...si se logra la subsistencia en base a los propios recursos, esfuerzos y trabajos, se alcanza conjuntamente un nivel insospechado de autonomía y de libertad de operación, que no se puede permitir a sí misma ni siquiera unidades económicas y organizaciones sociales, 
gremiales y politicas poderosas que mantienen complejos y múltiples lazos con el mercado y con el sistema político (Razeto, 1986).

En esta discusión, Ortega y Tironi (1988), motivados por conocer cómo potenciar el esfuerzo de los pobres a través del estudio de los Pobladores, generan una posición intermedia entre estas dos visiones. Por un lado, constatan los tres principales problemas de las OEP, a saber: las formas en cómo ellas orientan y organizan la producción, los canales de comercialización a los cuales están ligadas y las condiciones de su autonomía operativa. Por otro lado, aprecian que este tipo de experiencias representa una oportunidad para establecer una estrategia de superación de la pobreza que debería ser asumida ya no exclusivamente por los sectores populares urbanos y las instituciones donantes, sino que también por las políticas públicas implementadas desde el Estado.

En este sentido, el punto de mayor relevancia para ellos lo constituye el cómo potenciar la autonomía de este tipo de organizaciones, compartiendo la preocupación de Razeto y Hardy sobre estos asuntos en el nuevo contexto político que Chile vivirá a partir de 1990.

La tentación de solucionarlas por la vía del asistencialismo y de políticas de promoción social, al margen de todo intento de protagonismo de los mismos sectores involucrados, está siempre presente, tanto en aquellos sectores políticos que tradicionalmente concentraron en el Estado los mecanismos de inclusión social y económica, como también en algunos sujetos populares más necesitados (Razeto y Hardy, 1985).

Desde las conclusiones que hasta aquí hemos señalado, podemos observar que las actividades económicas autogestionadas están estructuradas sobre tres órdenes. Uno económico, donde se encuentran los insumos de la actividad 
comercial; otro social, en el cual se ubican las formas que adoptan las relaciones entre los trabajadores, especialmente mujeres que no han experimentado la desalarización y desproletarización, y aquellas que permiten concretar la solicitud de créditos y las actividades que generan bienes colectivos; $y$, finalmente, un orden cultural, en el cual están los modos de vinculación de las informaciones técnicas que hacen posible producir y las estructuras normativas que delimitan las conexiones de los valores que evalúan las relaciones como de cooperación, reciprocidad y (o) donación y que, en base a los resultados de tales ejercicios, organizan simbólicamente el espacio local.

Estas actividades económicas autogestionadas se encontrarían influidas por el ritmo que adquiere la dinámica del sistema social local, inicialmente marcado por las condiciones en las cuales el mercado de consumidores obtiene sus ingresos, mayoritariamente conformado por hombres que experimentan la desalarización y desproletarización; la racionalidad sobre el consumo que impera en las familias y la entrega de servicios de capacitación y crédito de organizaciones que, no siendo dependientes del ritmo de las dinámicas locales, sí dan forma al sistema de relaciones que ahí sucede.

Ahora bien, esta relación de dependencia no sólo es probable como ha sido señalada, sino que, a la inversa, es decir, asumiéndolas como actividades económicas que, en mérito de su margen de autonomía, se transforman en actores económicos que ayudan a reproducir el sistema de relaciones sociales locales. En este punto, los investigadores que trabajan desde el concepto "Popular" le asignan un objetivo sociopolítico de transformación de las desigualdades sociales y económicas.

Esta situación es comprensible si observamos que, en el último cuarto de la década de los ochenta, la variable sociopolítica de participación cívica cruza significativamente 
las actividades cotidianas de amplios sectores sociales. De esta manera, las actividades económicas autogestionadas, así como otras formas de Organizaciones Económicas Populares, ligaron sus objetivos comerciales con los de la organización social de protesta. Esta relación de propósitos, que si bien puede tender a desaparecer en un nuevo escenario político, no cumpliendo las expectativas de los investigadores según los datos con que disponen para la época, es factible de visualizar como la puesta en práctica de las capacidades sociales que trascienden en busca de un beneficio colectivo, a saber: Democracia, lo que incide en el desenvolvimiento del ser social de las unidades económicas.

Esto es relevante cuando entramos a comprender el proceso de construcción de identidad de las actividades económicas autogestionadas, o de cómo es valorada y hecha práctica la interrelación entre los tres ordenes que la constituyen. Debido a que es posible identificar que sus propietarios, miembros o trabajadores, pueden presentar prácticas especialmente discursivas que explícitamente dan cuenta de estar transformando su orden económico, social y (o) cultural o las relaciones del sistema en donde se encuentran pero que, implícitamente, generan efectos contrarios que refuerzan lo que dicen transformar.

Éste y los anteriores aspectos tratados serán retomados durante los noventa en un marco mayor de estudios y ensayos. Al respecto, Mezzera reconoce que ha existido un amplio debate cargado de matices ideológicos, donde los partidarios de los sectores de derecha insisten en hablar sólo de "microempresas", mientras que los vinculados a posiciones opuestas prefieren la expresión"economía popular". Frente a esto, advierte que, desde 1973, el Programa Regional del Empleo para América Latina y el Caribe (PREALC) había utilizado el concepto de Sector Informal para estudiar la "vinculación entre la segmentación del mercado de bienes y la que se registra en el mercado laboral." (Mezzera, 1993) Y que, 
a principios de la década de los ochenta se empleó el de Economía Informal con el propósito de distinguirla de la Economía Subterránea, la que comprende a las personas y organizaciones que no son pobres y que se dedican a violar las leyes laborales y a estafar al Fisco.

Para esta posición, el Sector Informal Urbano está compuesto por unidades productivas con pocas probabilidades de obtener capital, donde se utiliza el excedente de oferta de trabajo y presenta una activa relación comercial con el sector moderno de la economía. En él, habría unidades productivas que tendrían condiciones para incorporarse al crecimiento económico y a la modernización, o al "circuito superior" que produce bienes y servicios de alta calidad y que vende a precios que permiten el ahorro y la inversión; mientras que existirían otras que estarían destinadas a desaparecer y cuyos trabajadores serían absorbidos por las unidades económicas modernas.

Van Hemelryck (1993) reconoce que es adecuado denominar Sector Informal a este conjunto de unidades económicas, señalando que ésta recoge la especificidad de los aportes conceptuales presentados a través del sector de microempresas y no estructurado, en el sentido que apunta a identificar a un conjunto de unidades pequeñas que son el principal medio de vida para sus propietarios, los cuales utilizan poco capital y recurren a los miembros de la familia para realizar las actividades económicas. Pero, además, este autor abre la posibilidad de considerar a los tres parámetros que han permitido definir al Sector Informal: número de trabajadores y valor de las ventas y del capital fijo, desde un sentido distinto, encaminado a observar las sutilezas de sus funcionamientos basados en las acciones de emprendimiento que las transformarían en instancias organizadas de control y decisión.

Según este planteamiento, se pueden clasificar las empresas en tres categorías: las que dependen de una persona 
o un grupo de personas que delega parte del proceso de toma de decisiones y que no están presentes en la unidad productiva; las que dependen de una persona o de un grupo de personas que sí trabajan físicamente en la empresa y que participan activamente de todos los aspectos de la toma de decisiones; y aquellas en que las personas son los dueños y elementos constituyentes del sistema, distinguiéndose, ahí, las empresas familiares, incluyendo los trabajadores por cuenta propia y las empresas de trabajadores, siendo ambos tipos "autogestionados".

Compartiendo este planteamiento, Benavente (1993) reconoce a las primeras como propiamente pequeñas empresas y las denomina de "reproducción ampliada": poseen mano de obra asalariada y calificada y presentan capacidad de ahorro y rotación de capital. A las últimas, él las nombra de "subsistencia" y las describe como actividades que aseguran ingresos escasos e inestables a sus dueños, utilizan mano de obra no calificada y tienden a descapitalizarse rápidamente.

Por su parte, Calderón (1993) discute la homogeneidad que a través de los anteriores conceptos se le pretende asignar a las distintas manifestaciones que presentaría este tipo de organizaciones, aludiendo a las características de su racionalidad económica basada en el trabajo, relaciones laborales directas y el doble atributo de emprendedor y trabajador de quienes las dirigen, las que serían comunes y simultáneas en los artesanos, microempresarios, campesinos, pescadores artesanales y pirquineros; y que no se encontrarían, a la vez, en las que se nombran bajo los conceptos de Pequeñas y Medianas Empresas (PYME).

Debido a esto, Calderón propone usar el término de "pequeña producción" para englobar el conjunto de estas experiencias y reservar el de microempresas para un tipo particular ubicado en el área urbana, dedicada a la manufactura, construcción y servicios y que se encontraría 
conformando una identidad social diferente a las que se habrían articulado durante la década de los ochenta.

De esta manera, a través de la década de los noventa se extenderá un escenario donde las distintas comunidades científicas debatirán sobre las dimensiones que han de definir a las actividades económicas autogestionadas. Como producto de estos ejercicios, se constatan las variables que ya habían sido identificadas y, a medida que el objeto de análisis comienza a ser abordado por estudios multidisciplinarios que incorporan criterios cualitativos y explicaciones multicausales, aparecen dimensiones intensivas y variables que sólo son revisables en términos de proceso.

Sobre la tendencia que sigue el debate, es posible visualizar que las actividades económicas autogestionadas se ubicarían desde una posición de ilegalidad o informalidad en el sistema de relaciones sociales, lo que les impide acceder en mejores términos a los servicios de créditos para realizar inversión; y, a la vez que tienen una relación de dependencia con el mercado de consumo, presentan una activa relación con el sector moderno y legal de la economía.

En dicho sistema, su orden económico presenta un capital escaso y de bajo valor, además de pocas posibilidades de generar ahorro e inversión y una producción de calidad media y baja. En tanto que su orden social está basado en relaciones laborales directas entre trabajadores no calificados o bajamente calificados, los que además se encuentran vinculados por el parentesco, observándose que, al menos, uno de ellos, principalmente mujeres, presenta el doble atributo de emprendedor y trabajador; $y$, debido a la calidad de las interacciones, es posible que sucedan procesos de socialización a través de los cuales se instruye a los miembros sobre los oficios y la racionalidad que inspira el ejercicio de los roles. Y, en su orden cultural, se ubica una racionalidad basada en el trabajo, en donde coexisten criterios particulares que permiten estimar precios a los 
productos y servicios; y se encuentran las relecturas de las experiencias que van delimitando la identidad y diseñando simbólicamente el espacio local.

Además, cabe suponer que las maneras de vinculación de los órdenes que constituyen a la actividad económica autogestionada, están insertos en un proceso que va mostrando qué relaciones generan beneficios que mejoran el control y la toma de decisiones, y utilidades que mantienen el giro comercial. Así, dicho proceso puede ser considerado como una trayectoria comercial que da cuenta de la capacidad de innovación en las vinculaciones entre los componentes de los órdenes, los cuales permiten a las actividades económicas hacer frente a las condiciones que señala el mercado de consumidores y las unidades económicas modernas. Sin embargo, hay que dejar en claro que, al menos por lo que hemos revisado, la trayectoria presenta una tendencia a la descapitalización.

\section{b) Factores que inciden en la trayectoria de las actividades económicas autogestionadas}

En este apartado, intentaremos identificar las variables presentes en la relación entre unidades económicas autogestionadas y Organismos No Gubernamentales (ONGs) que ofrecen servicios de créditos y capacitación. El antecedente de este tipo de programas se ubica a fines de la década de los setenta en las experiencias del economista bengalí Muhammad Yunus, el cual comienza a desarrollar, en 1976, lo que hoy en día se conoce como Grameen Bank; y en la del Banco Interamericano de Desarrollo (BID), cuyo Programa de Pequeños Proyectos se inicia en 1978.

Estas medidas, según Días (1993) y Yunus (1998), surgen por el nulo acceso que los responsables de las unidades económicas autogestionadas tienen para conseguir 
créditos de inversión en la banca tradicional. En Chile, Herrera (2003) observa que durante los noventa hubo una ampliación del acceso al crédito hacia este sector, debido a que, si en la década de los ochenta un 5\% tuvo acceso a este tipo de servicios, en los noventa éste aumentó entre un $18 \%$ y un $20 \%$, lo cual significa un incremento en el número de operaciones.

Este investigador identifica tres tipos de organizaciones que desarrollan estos programas, los cuales se diferencian por el volumen y naturaleza de sus activos y el desarrollo de su organización. Estos serían: grandes operadores, BancoEstado y Banefe; medianos operadores, Banco del Desarrollo y las cooperativas Coocretal y Liberación; y pequeños operadores, particularmente por ONGs.

Tomando en cuenta que nuestra reflexión está centrada en la relación entre actividades económicas autogestionadas y "pequeños operadores", mencionamos algunos elementos que, según Herrera, los caracterizan. A saber: presentan una experiencia de trabajo con las personas que tienen a cargo unidades económicas, sus actividades responden a las necesidades de los sectores excluidos de la sociedad, por lo que poseen misiones institucionales basadas en la rentabilidad social y económica; los promedios de monto por crédito y sus plazos tienden a ser similares a los bancarios, representan la única alternativa de crédito para las personas que habitan en las áreas periféricas, donde no llega la banca ni el sector cooperativo; carecen de fuentes propias de financiamiento y dependen fuertemente del trabajo de sus funcionarios y de los aportes estatales.

Según Herrera, la opinión de los usuarios de los servicios ofrecidos por "medianos operadores", nos muestra que los créditos permiten mejorar el bienestar de las familias, favorece la ampliación de la cartera de clientes y proveedores, mejora las ventas y utilidades y facilita la reparación de sus instalaciones. "Sin embargo, estudios más recientes indican que el crédito no cons- 
tituiría un elemento determinante en el desempeño económico de la microempresa en Chile. Una investigación de la consultora Focus, a una muestra de 520 microempresarios del Gran Santiago, concluyó que no existe evidencia estadísticamente significativa que permita relacionar los apoyos externos que recibió cada microempresa con su viabilidad y desempeño económico." (Herrera, 2003)

De lo anterior, es interesante retener, por un lado, que, a medida que se transita hacia un sistema sociopolítico donde hay más participación cívica, acontece una apertura en la manera de afrontar las actividades económicas generadas desde condiciones de pobreza. Ahí se valida, por ejemplo, la democratización del acceso al créditos de inversión. Por otro lado, el uso del crédito, al estilo de los "pequeños operadores", muestra su incidencia en el orden económico de las unidades productivas, al mejorar sus condiciones de producción y ampliar el mercado de clientes y proveedores, aunque queda en cuestión como herramienta para la mantención de los giros comerciales.

Esto último es constatado por los "pequeños operadores" a través del resultado que entrega el diagnóstico sobre las condiciones de sus usuarios. De ahí que existan alternativas de capacitación tendientes a mejorar este aspecto. En este sentido, y como última experiencia importante basada en el concepto de Organizaciones Económicas Populares, surge en 1989 el Programa de Formación y Especialización en Economía Popular y de Solidaridad - FACES, orientado a generar competencias en los equipos profesionales que constituyen a los organismos no gubernamentales: Programa de Economía del Trabajo (PET), Fundación Solidaridad Trabajo para un Hermano (TPH), Cooperativa de Ahorro y Crédito Liberación (CL) y Servicios Comerciales S.A. (SERCOM). Este programa tuvo tres momentos de implementación: 1990, 1991 y 1992.

Según Del Pino (1995), los principales problemas detectados en FACES de 1990, estuvieron relacionados 
con la coordinación de las distintas áreas temáticas y la heterogeneidad metodológica que los expositores utilizaron para dar cuenta de un "sector de la economía popular y solidaria", debido a lo cual, para 1991, los responsables del programa convocaron al Centro de Investigaciones de la Educación (CIDE) con el propósito de establecer, bajo la metodología de la Educación Popular, un piso mínimo de herramientas pertinentes a las realidades que se tenían en el trabajo en terreno.

Por su parte, Steigler (1993) advierte que las actividades de capacitación son importantes para los "pequeños operadores" pero, por el contrario, las personas a las cuales están destinadas parecen no valorarlas de la misma manera, debido a que su participación no es solamente baja, sino que principalmente desinteresada, y son evaluadas como informaciones teóricas, generales y no adaptadas a sus necesidades, por tanto, inútiles para la solución de sus problemas.

Estas apreciaciones responderían a un contexto más amplio, el cual estaría delimitado por la ausencia de hábitos de capacitación debido al abandono que este sector vivió durante la década de los setenta y ochenta, y por su disposición a suponer que este tipo de actividades estaría enmarcada bajo los parámetros de la educación formal, despertando así los recuerdos negativos y difíciles que ellos vivieron en la escuela.

De esta manera, sus principales conclusiones sostienen que las ofertas de capacitación son poco atractivas, debilitando la motivación de las personas para aprovecharlas, y que ellas no serían pertinentes a sus necesidades, por lo que se hace difícil lograr un cambio en sus comportamientos empresariales. En esos términos, no pone en cuestión la utilidad de la capacitación, sino que, más bien, la metodología que se usa para que las personas aprendan los contenidos que, a través de ellas, se pretenden entregar. 
Así, y entendiendo que las personas a las cuales se enfoca la capacitación son en su mayoría "autodidactas" que manejan algunos aspectos de la administración de sus unidades económicas, plantea la metodología del action learning. Esta metodología, conocida como CEFE (Competency based, Economies through, Formation of Entrepreneus), se orienta a potenciar capacidades que permiten a las personas tener una visión crítica de sus negocios y del contexto socioeconómico y sociocultural en donde éste se encuentra, así como aprender los conocimientos prácticos e instrumentos necesarios para iniciar y gestionar una empresa, para que ellos puedan dar respuestas oportunas y pertinentes a los múltiples problemas que presentan sus gestiones económicas, dentro de los cuales se encuentra: confundir la capacidad productiva con el volumen de ventas, sobrestimar su participación en el mercado y consideran que la estrategia de ingreso es siempre sinónimo de precios bajos y calidad alta; dar por hecho su viabilidad financiera y copiar al vecino los productos altamente tradicionales; su visión sobre la competencia como guerra a muerte; confundir las ventas con los ingresos y no tomar en cuenta los costos de preparación de los proyectos.

Finalmente, destacamos siete conclusiones a las cuales llega Ramírez (1999) cuando revisa las incidencias de las actividades de capacitación en gestión microempresarial en dos grupos de mujeres, uno de los cuales fue usado como control al no recibir informaciones referidas al género. La primera señala que estas actividades permitieron a las mujeres elevar su autoestima: "valorarme a mi misma", "desarrollar más mi personalidad", "quererme más a mi misma" y "sentirme persona". La segunda manifiesta que las utilidades estuvieron relacionada con la valoración de sus desempeños laborales, debido a lo cual pudieron fijar precios a sus productos y servicios y no regalarlos. La tercera está centrada en la capacidad que las mujeres instruidas en la gestión microempresarial con perspectiva de género fueron adquiriendo al interior de sus sistemas familiares para 
distribuir las labores domésticas, proceso que no lograron aquellas mujeres que constituyeron el grupo de control, ya que el sobrecargo de las tareas domésticas detuvo sus labores productivas y, en otros casos, sus vidas se encontraban sobre-explotadas.

La cuarta refleja que las mujeres de ambos grupos lograron establecer mecanismos diferenciados para resolver los conflictos y fijar procesos de negociación. La quinta diferencia a los grupos según el sentido atribuido a los tiempos de descanso, mientras que para las capacitadas en perspectiva de género los tiempos de recreación no son considerados como tiempos muertos, para las segundas, éstos están relacionados con sus propias actividades comerciales y productivas. La sexta expone que las mujeres sin perspectiva de género no llegan a ser conscientes de sus derechos, mientras que las del otro grupo, no sólo los conocieron sino que además los aplicaron al interior de sus familias y desempeños laborales. La séptima plantea que el total de las mujeres desconoce los beneficios que les corresponden por ser microempresarias, incluido el servicio de créditos.

Según lo expuesto por Steigler (1993) y Ramírez (1999), los Programas de Micro Crédito (PMC) y, especialmente, sus actividades de capacitación, implican un proceso de intervención que no sólo incide en el orden económico de las actividades comerciales autogestionadas, al entregar recursos frescos y facilitar el aprendizaje de herramientas técnicas que favorecen su gestión, sino que también sus órdenes social y cultural, al proporcionar espacios donde se hace posible que las personas ensayen sus capacidades de tolerancia, libertad, solidaridad, reflexión crítica y autocontrol, las que favorecen la ubicación de ellas en los sistemas sociales locales y permiten visualizar la envergadura de la autonomía de su actividad económica. Además, es probable que este tipo de encuentros incida en la trayectoria de las actividades económicas, ya que facilita la puesta a prueba 
de las vinculaciones posibles y útiles entre los componentes de los órdenes que la constituyen.

Finalmente, hemos de destacar el debate sobre el rol de los "pequeños operadores" en el sistema de relaciones en el cual se encuentran las unidades económicas, especialmente sobre su relevancia para apoyar actividades que generarían puestos laborales. En este sentido, observamos dos posiciones: una orientada a valorar el papel de las ONGs como instituciones pertinentes para las condiciones que presentan las unidades económicas del Sector Informal, y otra que señala que este tipo de propuestas no tiene ninguna importancia en materia laboral y para el crecimiento económico, por lo cual éstas deberían ser incorporadas a las operaciones de la banca y tratadas bajo las condiciones del Mercado Formal.

En esta última posición se ubican los planteamientos de Mezzera (1993) y Herrera (2003), los cuales, junto con reconocer la eficiencia de las ONGs que operan fondos rotatorios y las tasa de reembolsos de las personas que solicitan créditos, consideran que el crédito, en tanto herramienta eficiente para superar la pobreza, es un "espejismo", ya que no tiene un impacto estadísticamente relevante sobre la gestión de los negocios, el empleo y los ingresos.

Mezzera propone que es necesario usar este tipo de experiencias de apoyo para destinar recursos del mercado financiero formal de los países, ya que estos problemas devendrían como resultado del funcionamiento imperfecto de los mercados que harían posible la inequidad distributiva. Además de señalar que la disposición de las ONGs por ofrecer oportunidades de crédito podría estar induciendo a los "obreros-convertidos-en-microempresarios" a tomar estos recursos para producir bienes que en realidad no puedan venderse, al menos no al precio al cual el microempresario hizo sus cálculos, ya que este sector no sería independiente de las reglas de los mercados, sino que, más 
bien, se ubicaría como parte subordinada y dependiente de la economía general, condiciones que son constatadas también por Ramírez (1999).

En la primera posición se ubica Días (1993), Yunus (1998), Razeto (2002), Ossandón (2002), Troncoso y Santander (2002), los cuales comparten la importancia de la banca y del Estado como actores económicos promotores de estos servicios pero, con distintos énfasis, señalan que los PMC no sólo son herramientas apropiadas para generar empleos y realizar inversión en negocios de distinto tamaño y con diferentes trayectorias, sino que, además, se constituyen en instrumentos del Desarrollo al representar instancias donde las personas logran ser acogidas, pueden salir de la subordinación cultural de sus roles domésticos y ponen en funcionamiento capacidades que, sin este tipo de programas, sería poco probable que ellas las hubiesen valorado como importantes tanto para su crecimiento personal como para el mejoramiento de la calidad de vida de sus familias.

\section{c. De la espontaneidad de la gestión comercial al empoderamiento comercial}

Como hemos podido advertir, las actividades económicas autogestionadas se organizan sobre variables de distintos niveles, las cuales han sido ubicadas en el orden económico, social o cultural. A continuación, estimaremos que la mantención de las actividades económicas en los sistemas sociales depende del tipo de vinculación que se establece entre los órdenes, $y$, a medida que esto sucede, se va construyendo una trayectoria comercial.

Al inicio, podemos constatar que toda actividad económica autogestionada está orientada a obtener ingresos para satisfacer las necesidades de alimentación y salud de 
las familias e, inmediatamente, observamos que está basada en la mujer que no ha participado en las ofertas laborales del Mercado de Trabajo y, por ende, que en los últimos treinta años no ha experimentado procesos de desalarización y desproletarización, sino que, por el contrario, inicia una etapa de participación pública mediante el emprendimiento comercial, al ser propietaria de la actividad y trabajadora de la misma.

Esta etapa de génesis de la actividad económica autogestionada presenta cualidades que nos remiten a lo que Durkheim identificó como sistemas sociales con predominio de Solidaridad Mecánica, debido a que su desenvolvimiento se encuentra organizado desde las condiciones que plantea el espacio local, cuya dinámica está marcada por la precariedad y discontinuidad de los ingresos y donde predomina una racionalidad económica basada en la resolución de problemas.

Así podemos constatar que en la génesis, la organización del orden económico se encuentra al interior de la vivienda de la dueña de la actividad comercial y, eventualmente, en un espacio urbano no diferenciado del equipamiento público; se sustenta en los escasos ahorros que permiten comprar insumos en aquellos establecimientos que se usan como "vecina" o "dueña de casa" , la producción es de baja calidad y se ofertan productos y servicios comunes a los de las otras unidades económicas del espacio local, y los canales de comercialización se establecen mediante los contactos familiares y vecinales.

En este momento, el orden social está basado en el rol que la mujer desempeña al interior de la economía doméstica, sin la presencia de una organización especializada para producir; $y$, en el orden cultural, predominan criterios que no permiten maximizar los recursos, especialmente al concebir la fijación de los precios en razón de lo que otros estiman; y las evaluaciones de reciprocidad, cooperación 
y donación que se han hecho como "vecina", establecen los parámetros que organizan simbólicamente el espacio local.

Además, en esta génesis, se encuentran los primeros ejercicios de constatación y refutación de las relaciones entre los componentes de los órdenes y, a medida que reportan utilidades que mantienen el giro comercial, incitan a la persona a presentarse en los encuentros cotidianos desde su posición de responsables de la actividad económica. Este proceso implica una reorganización de la identidad de la que lleva a cabo la tarea comercial, la cual está mediada por una capacitación que se compone de varios momentos en los cuales se aprecian las capacidades de gestión.

Estas actividades evaluativas constituyen aprendizaje en lo que podríamos denominar como resiliencia, es decir, donde las personas potencian la confianza en sí mismas y re-elaboran su sentido positivo de futuro. De esta manera, la reflexión nos lleva a plantear que la separación de la etapa de génesis de la actividad económica autogestionada se produce en la medida que el orden cultural formaliza mecanismos que permiten revisar lo que ha sucedido y transforma en rutinas las vinculaciones eficientes de los órdenes para la gestión comercial.

Este nuevo componente del orden cultural es posible de describir a través de la idea de cocoon protector de Giddens (1996), el cual permite a la persona considerar la realidad cotidiana como totalidad, aumentando las posibilidades de maniobra que esta irá visualizando para elegir los posibles medios a utilizar para afrontar los problemas y, a la vez, favorece la incorporación de estructuras de sentidos que generan beneficios.

En esas circunstancias, las interacciones que suceden entre la actividad económica autogestionada y las organizaciones económicas y sociales de similar o mayor tamaño representan nuevos momentos de la capacitación, toda vez 
que se transforman en procesos de socialización mediante los cuales se logra distinguir que la "realidad total" es posible en la medida que está compuesta por sistemas de relaciones específicas.

Así, el orden económico de la actividad autogestionada asume que el "fiado", versión del crédito de consumo, es eficiente como estrategia de comercialización en las condiciones del mercado de clientes, sabe lo que representa para sus utilidades esta dependencia y la que mantiene con los proveedores, antecedentes que disponen a buscar alternativas para aumentan la diversidad de los productos y/o servicios que ofrece y para mejorar la calidad de las instalaciones. Mientras que los miembros de la familia se ubican desde actividades que atraen clientes e informaciones que permiten abaratar los costos, la responsable del emprendimiento se abre a la búsqueda de oportunidades para fortalecer su orden económico.

Hasta este punto, la trayectoria de la actividad económica autogestionada ha visto incrementada su autonomía, observándose que el desarrollo de la administración económica y social es propiamente endógena, derivada del uso probable de las relaciones entre sus componentes. Sin embargo, se observa que se encuentran en latencia las posibilidades de innovación que hacen factible el surgimiento de componentes especializados, los que permitirían trascender la tendencia a la descapitalización, vía aumento de la demanda y de los precios.

En este punto, es necesario identificar la influencia que pueden ejercer "otros" que, no siendo dependientes de las dinámicas del sistema local, sí ayudan a producirla. Así, es posible definir las actividades que implementan los “pequeños operadores" de créditos. Éstos, si bien son reconocidos por entregar capital para realizar inversión, con lo cual rompen la inaccesibilidad a este tipo de servicios por parte del Sector Informal, apoyan y fortalecen la especia- 
lización de los ordenes social y económico al institucionalizar las actividades habituales mediante la herramienta Plan de Negocios. Estas experiencias permitirían poner de manifiesto la mayor complejidad que iría adquiriendo cada orden a través del desarrollo de la autonomía en la trayectoria, acercando a la actividad económica autogestionada a un estado próximo a lo que Durkheim identificó como Solidariad Orgánica.

Entonces, sería probable encontrar que el orden económico ha establecido una línea de crédito, mecanismos de evaluación periódica de la rentabilidad, donde se ubican los cuadernos que registran las ventas; presenta estimaciones de ahorro, aumenta la calidad de la atención al cliente mediante la formalización de estrategias de comercialización como, por ejemplo, "el fiado", la "yapa" y los onomásticos; se diversifican las existencias y se cuenta con variados proveedores. En el orden social, no habría nuevas plazas laborales, sino que, más bien, se consolidarían las que ya existen; se formalizarían canales de comunicación que permiten educar a los nuevos miembros en los oficios, y se instauran mecanismos de control organizacional que delimitan las funciones.

$Y$, en el orden cultural, el "hacer negocio" funciona como eje de sentido eficiente, es decir, siguiendo a Bourdieu (1998), es una estructura estructurante de sentidos de acción y de disposición para la acción, desde donde se origina una visión de mundo en la que coexisten criterios particulares de vinculación de las informaciones técnicas que hacen posible producir, permiten estimar los ritmos de la demanda y fijar los precios; y donde se encuentran las relecturas de las experiencias que van delimitando la identidad de la responsable de la actividad comercial desde una situación de informalidad e ilegalidad, y ya no como "dueña de casa", "vecina" o consumidora".

En este nuevo estado, asumiría una mayor relevancia el orden social de la actividad económica, debido a que la 
mujer, al ver los beneficios que le acarrea la ampliación de los contactos, destinaría mayores recursos para establecer proximidades sociales. Por tanto, aquí se vuelven clave los factores que permiten generar confianzas; entre ellos, cabría mencionar: las estrategias mediante las cuales la proximidad social de los otros disminuye o aumenta, cuando el agente se siente capacitado en aptitudes que le facilitan el acceso a redes locales de apoyo que lo integran y cuando su saber común, o teorías surgidas de la vida cotidiana; y lo que aprende, o informaciones técnicas obtenidas mediante cursos de capacitación de distinto tipo, encuentran nuevas oportunidades para ser puestas a prueba.

Desde estos aspectos, progresivamente, el orden social construiría proyectos de vida en los cuales se incorporará a las personas que componen los grupos secundarios locales. En este sentido, el concepto de red, entendido como los sistemas abiertos que a través de un intercambio dinámico entre sus integrantes y con otros grupos sociales, posibilitan la potenciación de los recursos que poseen (Dabas, 1993), constituye una aspecto clave para comprender los beneficios que vendrían con las capacidades asociativas.

Al respecto, Lomnitz (1998) destaca que estas redes de intercambio recíproco, que se dan en el Sector Informal de la economía, operan sobre la base de lazos de confianza y constituyen una suerte de "stock" de relaciones reales o potenciales, heredadas o acumuladas, ordenada como mapa cognitivo en la mente de las personas de acuerdo a lo que socialmente se de fine como distancia social o confianza. De forma que este tipo de relaciones representa, para los individuos, un elemento relevante del capital social.

Este capital social, según Durston, compuesto por las normas, instituciones y organizaciones que promueven la confianza, favorecería la ayuda recíproca y la cooperación, las que, en conjunto, pueden contribuir a tres tipos de beneficios: reducir los costos de transacción, producir beneficios 
públicos y facilitar la construcción de organizaciones de gestión de base efectivas, de actores sociales y de sociedades civiles saludables.

En resumen, cabe concluir que toda actividad económica autogestionada cuya trayectoria va potenciando la autonomía, permitiendo que se especialicen los órdenes económico, social y cultural a través de innovaciones que surgen de un desarrollo endógeno, se aproxima a un estado social en el cual predominan relaciones que pueden ser consideradas como expresiones de Solidaridad Orgánica. En este punto, que no es sino la antesala de su participación económica organizada, el ser social que ha ido elaborando la incita a vincularse activamente con otros para mejorar la producción y comercialización y para aprovechar las oportunidades que le ofrece el entorno para especializar su capital humano. Paralelamente, abre los escenarios sociopolíticos locales y comunales, donde ubica su visión de mundo en la implementación de las políticas públicas que fomentan las actividades económicas, a través de las cuales pone en cuestión el libre juego de la oferta y la demanda mediante la revisión que hace de los otros actores que generan monopolios.

\section{Bibliografía}

Agurto et al.

Baber, B.

Benavente, $\mathrm{R}$,

Berger. P y Luckmann, T.

BID.

Bourdieu, P
"La educación Popular en Chile Hoy. Elementos para definirla", Educación y Solidaridad n n 3, Santiago, ECO, 1983.

"The Logic and Limits of Trust", New Jersey: Rutgers University Press, 1983.

“Microempresa y asociatividad.” En Proposiciones n²3: Microempresa y desarrollo. Sur ediciones. Chile. Santiago, 1993

"La Construcción Social de la Realidad". Ediciones Amorrortu, 1980.

"La microempresa y el BID. El crédito a quién corresponde”. En Proposiciones n²3: Microempresa y desarrollo. Sur ediciones. Chile. Santiago, 1993.

"Por una Antropología Reflexiva". Ediciones Grijal- 
Burki, J., Shahid,

Calderón, Carlos:

Campero, Guillermo.

Cerda, Luz y Cifuentes, Max.

Collier, Poul.

Contramaestre, D. Leighton, A, y otros.

Dabas, A.

De Soto, Hernando.

Del Pino, Jaime.

Días, Carlos.

Dirven, Martine.

Durkheim, Emile. (1960)

Durston, John.

Fondo de las Américas.
"Construyendo Confianzas para una Economía Solidaria”. Síntesis Seminario Internacional. Distribuye Vicaria de Pastoral Social, Chile. Santiago. 2002.

bo, Santa Fe de Bogotá, 1998.

"Changing Perceptions and Altered Reality, Emerging Economies in the 1990s," The World Bank, 2000.

"Ideas y proposiciones para un Plan de fomento a la pequeña producción”. En Proposiciones $\mathrm{n}^{\circ} 23$ : Microempresa y desarrollo. Sur ediciones. Chile. Santiago, 1993.

"Organizaciones de pobladores bajo el régimen militar”. En Proposiciones $n^{\circ} 14$ : Marginalidad, movimientos sociales y democracia. Sur ediciones. Chile. Santiago, 1987.

“¿Qué comen los pobres? Hábitos alimenticios, estrategia de compra y mecanismos de sobrevivencia." Ediciones Instituto de Sociología de la Pontificia Universidad Católica de Chile. Chile. Santiago 1987

"Social Capital and Poverty". In Social Capital Initiative Working paper $n^{\circ} 4$, Word Bank, 1998.

"Redes Sociales". Ediciones Grijalvo, Argentina. Buenos Aires, 1999.

“El otro sendero.” Ediciones el Barroco. Perú. Lima, 1986.

"Formando para una economía de solidaridad y trabajo.” Ediciones PET. Chile. Santiago, 1995.

"Programa de la agencia de los Estados Unidos para el Desarrollo Internacional (USAID) en América latina de apoyo a la micro empresa". En Proposiciones $n^{\circ} 23$ : Microempresa y desarrollo. Sur ediciones, Chile. Santiago 1993.

"Complejos Productivos, apertura y disolución de cadenas”, Apertura Económica y desencadenamientos productivos - Reflexiones sobre el complejo lácteo en América Latina. Libro CEPAL N 61 , Santiago de Chile.

"Entre el Ideario y la Realidad: Capital Social y Desarrollo Agrícola". Conferencia: "En busca de un nuevo paradigma: capital social y reducción de la pobreza en América Latina y el Caribe". Santiago de Chile, 24 al 26 de septiembre de 2001.

De la división du travail social, PUF. Versión castellana: La división del trabajo social.

“Construyendo capital social comunitario". En Revista de la CEPAL, $n^{\circ}$ 69, diciembre 1999. Chile. Santiago

“¿Qué es el capital social comunitario?. CEPAL, División de Desarrollo Social, Serie Políticas Sociales, $\mathrm{N}^{\circ}$ 38, 2000. Santiago de Chile.

“Participación, Superación de la Pobreza y Desarrollo Sustentable. Aprendizaje de los Fondos Sociales y Ambientales de América Latina y el Caribe". Ediciones Fondo de las Américas, Santiago de Chile, 2000. 


\section{LECTURAS POSIBLES SOBRE LA CONSTRUCCIÓN DEL ACTOR ECONÓMICO \\ Nicolás Gómez Núñez}

Fukuyama, Francis.

“Confianza”.Ediciones Atlántida, Argentina, Buenos Aires 1996.

"La Gran Ruptura. La naturaleza humana y la reconstrucción del orden social”. Ediciones Atlántida. México. 1999

Fundación Nacional para la Superación de la Pobreza.

"Un enfoque global de la pobreza y de su medición." Ediciones Fundación Nacional para la Superación de la Pobreza. Santiago, 1999.

Giddens, Anthony.

"Modernidad y autoidentidad", en Josetxo Berianin (Comp). Las consecuencias perversas de la modernidad. Ediciones Antropos, 1996

Gómez, Luis.

"La sombra de los gozos. Modernidad y crisis del Estado de Bienestar”. Ediciones Universidad Autónoma de Baja California. México, DF, 1993.

González, Raúl. "Desarrollo productivos locales y pequeña producción.” En Proposiciones ${ }^{\circ} 23$ : Microempresa y desarrollo. Sur ediciones. Santiago, 1993.

Güell, Pedro ., "Subjetividad social y Desarrollo Humano: desafíos para el nuevo siglo", en Jornadas de Desarrollo y Reconstrucción Global, (1998) SID/PNUD, Barcelona.

Guzmán, Virginia, Mauro, Amalia y Araujo, Kathya.

"Trayectorias laborales de mujeres". Ediciones Centro de Estudios de la Mujer, CEM, Santiago de Chile, 1999.

Hardy, Clarisa.

“Hambre + Dignidad = Olla Común.” Ediciones PET. Santiago, 1985.

“Estrategias organizadas de subsistencia. Los sectores populares frente a sus necesidades en Chile." Ediciones PET. Santiago, 1985.

Herrera, Andrés.

“Crédito a la Micro empresa en Chile. Una revisión cualitativa. (1991-2001).” Ediciones PET. Santiago, 2003.

Kliksberg, Bernardo.

"Capital social y cultura, claves esenciales del desarrollo”. En Revista de la CEPAL, n 69, Santiago de Chile, diciembre 1999.

"Diez falencias sobre los problemas sociales en América Latina”. En Socialismo y Participación, N 89. Perú, Lima, diciembre 2000.

Lechner, Norbert, "Desafíos de un Desarrollo Humano: individualización y capital social “ En Instituciones y Desarrollo, No.7, Http: www. iigov.org/htm

Leiva, Fernando.

"Los límites de la actual estrategia de lucha contra la pobreza y el dilema de las ONG's." Ediciones PAS. Santiago de Chile, 1995.

Márquez, Fernando. "El proyecto de la cultura de la empresa: ¿ nuevos términos para una vieja historia?" En Proposiciones

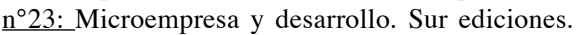
Santiago de Chile, 1993.

Mezzera, Javier.

“Experiencias de apoyo al sector Informal Urbano." En Proposiciones n²3: Microempresa y desarrollo. Sur ediciones. Santiago de Chile, 1993.

Misztal, Barbara A. Trust in Modern Societies, Cambrige: Polity press, 1996. 
Niño, Lya.

Ramírez, Marisol.

Ramírez, Apolonia.

Razeto, L.

"Empoderamiento de las mujeres indígenas asentadas en: Tijuana y San Quintín, BC.” Mimeo, Doctorado en Ciencias Sociales Universidad Autónoma de Baja California. Mexicali, Febrero 2003.

Ortega, Eugenio y Tironi, Ernesto. "Pobreza en Chile”. Ediciones Centro de Estudio del Desarrollo. Santiago de Chile Santiago, 1988.

"Desarrollo y Cultura. Una visión crítica de la modernidad en América Latina y el Caribe”. En Estudios Básicos de Derechos Humanos VI. Ediciones Instituto Interamericano de Derechos Humanos, San José. 1996.

"Dos Modelos de Capacitación en Gestión para Microempresarias”. Ediciones Fundación de Ayuda Social de las Iglesias Cristianas, FASIC. Santiago de Chile, 1999.

"Comprando juntos frente al hambre”. Ediciones PET. Santiago, 1986

"Economía Solidaria y Mercado Democrático." Ediciones PET. Santiago de Chile, 1984.

"Critica de la economía, mercado democrático y crecimiento". Ediciones PET. Santiago de Chile, 1984.

"Economía popular de solidaridad. Identidad y proyecto en una visión integradora”. Ediciones Área Pastoral Social de la Conferencia Episcopal de Chile. Santiago de Chile, 1986.

"La Economía de solidaridad en su proyecto de transformación social”. En Proposiciones $n^{\circ} 14$ : Marginalidad, movimientos sociales y democracia. Sur ediciones. Santiago de Chile, 1987.

Razeto, L. Klenner, Arnol, Ramírez, Apolonia y Urmeneta, Roberto.

“ Las Organizaciones Económicas Populares 1973

- 1990”. Ediciones PET. Santiago de Chile, 1990.

Revista Proposiciones. "Marginalidad, Movimientos Sociales y Democracia”. Ediciones Sur. Santiago de Chile, 1987.

Ruiz-Tagle, J. y Urmeneta, R. "Los Trabajadores del empleo Mínimo". Ediciones PET. Santiago de Chile, 1984.

Steigler, H.

"Acting Learning - Aprender Haciendo". En Proposiciones $n^{\circ} 23$ : Microempresa y desarrollo. Sur ediciones. Santiago de Chile, 1993.

Tironi, Eugenio. "Pobladores e integración social”. En Proposiciones n¹4: Marginalidad, movimientos sociales y democracia. Sur ediciones. Santiago de Chile, 1987.

Troncoso, Deiza y Santander, Hernán.

"Solidaridad y Trabajo. Una experiencia posible". Ediciones Fundación Solidaridad Trabajo Para un Hermano. Santiago de Chile, 2002.

Van Hemelryck, L.

"Microempresa, Pequeña Producción y Sector Informal." En Proposiciones n ${ }^{\circ} 23$ : Microempresa y desarrollo. Sur ediciones. Santiago de Chile, 1993.

Vives, Cristián. "Crisis en la familia popular, y su visión de futuro". Ediciones Centro Bellarmino. Santiago de Chile, 1983.

Universidad Nacional Autónoma de México.

"Estudio para la creación de la Banca comunitaria 
LECTURAS POSIBLES SOBRE LA CONSTRUCCIÓN DEL

ACTOR ECONÓMICO

Nicolás Gómez Núñez

Urrutia, M.

Villarreal, Magdalena.

del Distrito Federal." Ediciones UNAM, junio de 2001.

"Familias Populares. Historia Cotidiana e Intervención Social", Ediciones ECO, Educación y comunicación. Santiago de Chile, 1997.

"Puercos, Gallinas, Vacas y Maridos: La naturaleza del capital en las microempresas de las mujeres campesinas." Ponencia presentada al XXI seminario de economía agrícola del Tercer Mundo. UNAM, 2001 